\title{
Abortos e Infanticidios: Tensiones y debates en la legislación penal moderna (1886-1968)
}

\section{Abortions and Infanticides: Tensions and discussions in modern criminal law (1886-1968)}

\author{
María Sol Calandria \\ Universidad Nacional de La Plata \\ Consejo Nacional de Investigaciones Científicas y Técnicas \\ sol.calandria@gmail.com \\ (Argentina) \\ Nadia Florencia Ledesma Prietto \\ Universidad Nacional de La Plata \\ Consejo Nacional de Investigaciones Científicas y Técnicas \\ nadialedesmaprietto@yahoo.com.ar \\ (Argentina)
}

\section{Resumen}

En Argentina a fines del siglo XIX se produjo una importante racionalización de las prácticas punitivas que tuvo como resultado la formación del nuevo sistema penal moderno.

Tres aspectos de la reproducción biológica fueron criminalizados: el aborto y el infanticidio, como delitos contra las personas, y el abandono de niños/as, como delitos contra las garantías individuales. Estas reformas demostraron una situación jurídica particular de las mujeres; el aborto e infanticidio fueron considerados delitos que atacaban los intereses del Estado y desnaturalizaban el presunto instinto maternal.

Este trabajo analizará las tensiones genéricas que subyacieron en la legislación penal en torno al aborto e infanticidio, evidenciando los cambios en la relación mujeres- Estado. Se examinarán debates legislativos, 
proyectos y reformas al Código Penal desde su sanción nacional en 1886, hasta 1968, cuando se incorporó la violación, como causa de aborto no punible y fueron excluidos los familiares como posibles perpetradores de infanticidio.

Palabras Clave: aborto; infanticidio; sexualidad; legislación penal

\begin{abstract}
At the end of the $19^{\text {th }}$ century, there was an important rationalization of punitive practices that resulted in the formation of the new modern criminal system in Argentina. Three aspects of biological reproduction were criminalized: abortion and infanticide, as crimes against people, and the abandonment of children, as crimes against personal guarantees. These reforms demonstrated a particular legal status of women; abortion and infanticide were considered crimes that attacked the interests of the State and altered the presumed maternal instinct.

This paper analyzes underlying tensions regarding gender issues in the criminal law about the legal concept of abortion and infanticide to show the changes in the relationship between women and the State. We study parliamentary debates, projects and reforms of the criminal legislation, from its first national sanction in 1886 to 1968, when rape was incorporated as a cause of non-punishable abortion and excluded family members as possible perpetrators of infanticide.
\end{abstract}

Keywords: abortion; infanticide; sexuality; criminal law

$$
\propto \ddot{e} \propto
$$

\section{Introducción}

Durante los ochenta y dos años que transcurrieron entre la sanción del primer código penal nacional, en 1886, hasta la ley de facto que reformó el Código Penal, en 1968, las figuras de aborto e infanticidio sufrieron diversas modificaciones. Estos cambios en la legislación argentina y los debates planteados en torno a ellos, han sido abordados de manera exhaustiva por juristas y especialistas del Derecho. ${ }^{1}$ De igual modo, el derecho penal codificado ha sido analizado desde distintos abordajes dis-

1. Véase: Zaffaroni y Arnedo (1996) y Levaggi (2012). ciplinares e intereses temáticos. Por ejemplo, desde la historia social, diversos trabajos han contribuido al estudio de la legislación penal y su aplicación en la provincia de Buenos Aires y regiones del país. ${ }^{2}$ Estos trabajos han abordado directa o colateralmente los cambios existentes en la legislación y la praxis judicial en el tránsito hacia la codificación dilucidando aquellas continuidades y rupturas que suscitó este proceso. Las pesquisas que se enfocaron en la criminalidad femenina en Argentina, han

2. Sobre este abordaje véase: Caimari (2012); Barreneche (2001); Yangilevich (2012); Sedeillan (2012); Corva (2014). 
puesto de relieve problemáticas específicas a través del análisis predominante de expedientes judiciales y publicaciones científicas. Pero, hasta el momento, es escaso el abordaje de otras fuentes documentales como los debates legislativos y proyectos de código. ${ }^{3}$ Por otra parte, numerosas investigaciones provenientes del campo de la historia de las mujeres y género, han estudiado las prácticas de aborto e infanticidio, $\mathrm{y}$ su relación con la maternidad y la reproducción. ${ }^{4}$ Sin embargo, la mayoría, se orientó hacia las prácticas de las mujeres y la praxis jurídica y médica al respecto.

Hay consenso en considerar que la sociedad argentina vivió la expansión de un proceso de modernización capitalista que, a partir de 1880, afectó directamente el campo del derecho a través de la codificación jurídica. La categoría de modernización ha suscitado numerosos debates para explicar el desarrollo capitalista y la emergencia del estado nacional argentino. Esto se debe a que algunos trabajos, teniendo como modelo la modernización europea, han comprendido la modernización en América Latina como un proceso histórico "desviado" e "inacabado". A diferencia de estas posturas, conceptualizamos como parte de un proceso de modernización, llevadas adelante por la elite gobernante las cuales estaban orientadas por las ideas ilustradas de ciencia, progreso y razón. Igualmente, entendemos que aquel proceso no fue lineal, ni unívoco y que las prácticas de la élite también produjeron numerosas consecuencias y exclusiones como la llamada "cuestión social”. ${ }^{5}$ Asimismo, siguiendo los planteos

3. Vassallo (2006b); Caimari (2007); Cesano y Dovio (2009); Di Corleto (2010); Calandria (2017).

4. Ruggiero (1994); Ini (2000); Nari (2004); Cepeda (2011); Calandria (2014); Ledesma Prietto (2016).

5. Para este tema, véase: Zimmermann (1995); Suriano de Verónica Giordano, podemos precisar que, en líneas generales, la modernización fue conservadora en términos de género. La autora señala entre sus características

la persistencia de la condición de inferioridad, que da cuenta del poder de una clase dominante tradicional (en el sentido de poseedora de una mentalidad anclada en el pasado y renuente al cambio profundo); la vía estatalista de tramitación de los procesos legislativos, que señala al Estado como principal agente de transformación; y, por último, y conectado con lo anterior, la incapacidad de la coalición de fuerzas que llevó adelante las reformas para incluir a los sectores organizados y movilizados en torno a demandas más radicales (Giordano, 2013, pp. 39-40).

Por ello, este trabajo se propone abordar esos denominados procesos de modernización y las relaciones de género en el período comprendido entre 1886 y 1968, cuando tuvieron lugar distintos proyectos autoerigidos como modernizadores que impactaron en el derecho penal y que modificaron las figuras de aborto e infanticidio. El análisis de la legislación desde una perspectiva de género nos permite ahondar en los conflictos que anteceden al establecimiento de la norma y evidenciar cómo las construcciones culturales permearon esa conformación de la legislación penal (Scott, 1985). Asimismo, pretende contribuir al esclarecimiento de tensiones y debates que se han desarrollado a lo largo del tiempo en nuestra legislación penal, podríamos decir, hasta la actualidad en el caso del aborto.

A través del Análisis Crítico del Discurso, se examinarán comparativamente los códigos penales sancionados, las modificaciones y

(2004). 
proyectos de reforma y los debates legislativos en el marco de la modificación de la ley. Esta perspectiva teórico-metodológica considera al discurso como una práctica social que debe analizarse teniendo en cuenta los procesos de producción e interpretación y el contexto social en el que éstos se producen. Entendemos que cada uno de aquellos procedimientos son una instancia que cristaliza el estado de las discusiones en torno a cómo la legislación penal y las condiciones sexo genéricas sobre el rol impuesto a las mujeres en la vida social, ligado a la reproducción y la maternidad, influyeron en la configuración discursiva. Por ello, el análisis del contexto social de producción y de las intertextualidades manifiestas o implícitas con otros géneros discursivos, en este caso, la intertextualidad entre el discurso legal, el médico y el científico, por ejemplo, nos posibilita entender cómo se construyen las normativas (Fairclough, 1992). El período seleccionado comienza en el año 1886 cuando se sancionó el primer Código Penal Nacional, elaborado en base al proyecto de Carlos Tejedor de 1867 que tuvo vigencia durante más de dos décadas en la Provincia de Buenos Aires-; y finaliza en 1968, cuando fueron eliminados los familiares directos como posibles perpetradores del delito de infanticidio y se incorporó la violación en general como causa de aborto no punible, modificando sustancialmente el tratamiento judicial histórico de estas figuras.

Estructuraremos el trabajo en tres momentos de la legislación penal. El primero, desde 1886 hasta 1921, cuando se introdujo la primera reforma del Código Penal; el segundo, desde 1921 hasta 1941 cuando el proyecto de José Peco introdujo nuevas interpretaciones sociales acerca de la maternidad y sexualidad que sirvieron de base para modificaciones posteriores; el tercero, desde 1941 hasta 1968 cuan- do la ley de facto recogió alguna de aquellas posturas y modificó la legislación vigente desde 1921. Compararemos distintas cuestiones para dilucidar los cambios existentes en los diversos códigos y proyectos. Por un lado, la definición de los delitos; por otro, sus penas y, por último, las fundamentaciones sociales en donde se enmarcaron estas figuras jurídicas.

\section{Límites en torno a la sexualidad femenina: maternidad y honra (1886-1921)}

La sanción del Código Penal, en 1886, representó la modernización del sistema penal, aunque también conservó elementos del sistema anterior como la pena de muerte (Levaggi, 2012, p. 257). Empero, excluyó de ésta a las mujeres debido a su capacidad gestante. La maternidad se transformó en un problema social frente a la necesidad de repoblar el territorio argentino, donde el Estado debía cumplir un rol activo como un aspecto fundamental de gobierno y comenzó a preocuparse por las practicas reproductivas de la población, la natalidad y la mortalidad infantil. En ese sentido, se tomaron una serie de medidas para su solución: por un lado, se impulsó una importante politica inmigratoria; y por otro, se promovieron una serie de politicas públicas que apuntaron al cuidado de las madres y los hijos. Fue en este momento histórico, cuando el rol asumido por el Estado en en la regulación de relaciones entre los sexos y familiares impactó directamente en las conductas reproductivas de las mujeres. Mediante el saber médico, la educación y el poder legislativo y judicial, intervino en la configuración de un proceso de la maternalización de aquellas. De este modo, las mujeres se transformaron en las responsables 
de los futuros ciudadanos y productores de la riqueza nacional (Nari, 2004).

En este contexto, la codificación penal tuvo un rol primordial al sancionar aquellas conductas de las/os ciudadanas/nos que se consideraron delictivas. Sin embargo, al hacerlo, diferenció penas y delitos para varones y mujeres que reforzaron los estereotipos de género y la domesticidad femenina obligatoria (Giordano, 2012).

Las salvedades construidas para las mujeres desde el derecho penal no pueden disociarse de otras esferas judiciales, especialmente de la legislación civil. Las mujeres, consideradas superiores moralmente e inferiores físicamente respecto del varón, debían ser juzgadas diferencialmente (Vassallo, 2006a). Se constituyeron delitos considerados "típicos" de las mujeres como el aborto e infanticidio cuyo fundamento se sedimentó en ciertos elementos percibidos como naturalmente femeninos: la debilidad y el sentimentalismo.

Estas concepciones heredadas del período anterior poseían una impronta propia de la moral católica y el control de la sexualidad ejercida por la Iglesia. Las Partidas, textos legales utilizados en materia penal hasta el siglo XIX en Argentina, ${ }^{6}$ no diferenciaron entre infanticidio $y$ parricidio, y establecieron para éste la pena de muerte, al igual que para el aborto -asimilado al infanticidio si se consideraba que el feto estaba animado, es decir, dotado de un alma inmortal que lo hiciese un ser humano (Sau, 1981). La gravedad de su falta y el castigo derivaban de una doble transgresión femenina, considerada delito y pecado, porque idealmente era pensada como un ser virtuoso (Juliano,

6. Véase: Barreneche (2001).
2009). Cuando el monopolio del control de la sexualidad ejercido por la Iglesia Católica cedió su primacía al Estado, el Derecho secular y los tribunales laicos heredaron estas concepciones configuradas culturalmente acerca de la mujer (Montero Cartelle, 2010). La codificación penal tuvo un lugar central dentro de los esfuerzos estatales para lograr que los individuos se ajustaran a los códigos de conducta hegemónicos, donde las propuestas ilustradas constituyeron el punto de arranque del derecho clásico o liberal convirtiendo a todo delito en una ofensa a la sociedad en su conjunto y el castigo en la defensa del contrato (Speckman Guerra, 2002). Desde ese lugar, se apuntó a normar las pautas de convivencia familiares a través de la regulación de las relaciones íntimas y la reproducción legítima en torno al modelo de familia patriarcal. Debemos mencionar entre otros indicadores de la creciente intervención estatal, la sanción de la Ley de Matrimonio Civil en 1888. Si bien para los defensores de la ley, ésta expresaba, como señala Verónica Giordano (2014), una moral "moderna" y quienes se oponían a ella respondían a una "moral superior" representada en la Iglesia Católica, en términos de género, "las mujeres estaban en una posición de subordinación” (pp. 393-394).

Estas nociones sexo-genéricas herederas de la moral católica en adición con la tendencia ilustrada, propia del siglo XIX y propensa a humanizar el castigo, configuraron penas reducidas para las mujeres en comparación con las que rigieron el actual territorio argentino desde la colonización. Las penas de infanticidio y aborto disminuyeron considerablemente a partir de la sanción del Código Penal redactado por Carlos Tejedor, entre 1865 y 1868, en el cual se estableció que las mujeres no podían ser ejecutadas ni condenadas a presidio y, si se trataba de una mujer honesta, debía ser arrestada en 
su casa. Por su parte, la pena de muerte para el aborto y el infanticidio fue suprimida, y en cambio, se asignaron penalidades de hasta diez años de penitenciaría y se consideró, para el infanticidio y el abandono, la causal del honor como atenuante. Esto se debió, según Adriano Prósperi (2016), a que la Ilustración dejó a los legisladores posteriores una noción atenuada singular para el crimen de infanticidio como fruto de dos causas concomitantes, la fragilidad femenina, por un lado, y la defensa del honor, por otro, cada uno de los cuales debía revelarse capaz de despertar la compasión del legislador. En este sentido, la honra, vertiente femenina del honor, en el contexto de codificación del siglo XIX, contuvo un componente modernizador concordante con las tendencias humanistas de reducción del castigo, emergentes al calor de la Ilustración. Al mismo tiempo que ocupó un lugar central para la atenuación de penas en los delitos de abandono e infanticidio cuando se consideraba que la madre había sido "ilegítimamente fecundada", pero no así para el aborto. En este sentido, era más grave decidir no ser madre que serlo y matar o abandonar al niño (Larrandart, 2000).

Las consideradas madres ilegítimas por la legislación eran aquellas que habían dado a luz fuera del matrimonio y que, por ende, el legislador supo que en este estado la mujer podía ser impulsada a delinquir por querer ocultar su falta. ${ }^{7}$ Esta categoría excluyó a las mujeres casadas ya que era inconcebible que quisieran deshacerse de un/a hija/o, naturalizando su rol doméstico maternal. Como señala Laura Klein (2005), "cuando una maternidad vergonzosa revelaría la sexualidad ilegítima de la mujer, el asesinato del hijo es atenuado al punto de

7. Para profundizar acerca del tratamiento legal de los hijos ilegítimos véase: Cosse (2008b, p. 32).

106 recibir menos castigo que un aborto", en cambio, la "deshonra sexual", no fue aplicada para el aborto en la misma medida que en el caso de infanticidio en el Código Penal, así, se desvinculaba la práctica del "sexo y la maternidad" (pp. 154-155). ${ }^{8}$

El aborto e infanticidio formaron parte de los llamados "delitos contra las personas" y fueron los que contemplaron las penas más bajas en el Código Penal dentro de este grupo. ${ }^{9}$ Sin embargo, Tejedor consideró al infanticidio como una figura autónoma cuyo móvil debía ser la deshonra frente a un nacimiento ilegítimo. Esto se prestó a numerosas discusiones entre juristas y agentes de justicia, principalmente, sobre cuáles eran los elementos excluyentes e incluyentes de la honestidad femenina. Si bien la legislación penal nunca definió exactamente a qué se refería con ello, la doctrina consideró que para que el atenuante o móvil se aplicase, las mujeres debían comprobar su honorabilidad, ya que no podían atribuirse a mujeres de corrompidas costumbres o mala fama anterior (Escriche, 1852 y Gonzalez Roura, 1922). Esto significaba que el atenuante no podía ser aplicado a mujeres que gozaban de una deshonra pública y conocida, entre ellas se encontraban las prostitutas y las que habían tenido hijos en análogas condiciones. Según Isabella Cosse (2008a), "la maternidad soltera era concebida una desviación", pues el vínculo matrimonial era considerado "el rito que permitía la

8. Véase anexo.

9. El homicidio simple fue penado con un mínimum de 10 años de presidio y con la pena de muerte o presidio por tiempo indeterminado si contemplaba el agravante del vínculo parental (ascendientes, descendientes, cónyuges). En este caso, las mujeres serían condenadas a penitenciaría por tiempo indeterminado debido a que, como establecía el código en su parte general, no podían ser ejecutadas ni condenadas a presidio. 
constitución plena de la identidad femenina" al ser esposa, ama de casa y madre, y también la identidad masculina "en tanto que convertía al varón en un jefe de familia con autoridad sobre la esposa y los hijos y la responsabilidad de satisfacer sus necesidades".

El límite entre el aborto y el infanticidio fue el nacimiento. Al fundamentar acerca de la diferenciación entre estos delitos, Tejedor (1871) manifestó tempranamente que el límite entre uno y otro era el parto, "el aborto acaba en efecto donde empieza el infanticidio, y es un delito menor que éste" (p. 218) y agregó que

es posible que una madre, inducida por una falsa vergüenza, crea prevenir, más bien que extinguir, la existencia de la criatura que lleva en su seno, mientras que dar muerte al hijo después de nacido es un acto de barbarie, cuyo horror no puede paliarse por ninguna ilusión. Esta distinción es evidente. La mujer embarazada no es todavía madre. No está retenida por el amor de una criatura que no conoce, y es más excusable cuando se deja arrastrar por el solo temor del deshonor (Tejedor, 1867, pp. 263-264).

Aquí, subyace un imaginario con respecto a la maternidad que trascendió lo meramente fisiológico y se ubicó en el campo de los sentimientos que debería poseer una mujer al momento del nacimiento del hijo, como el amor incondicional. Sin embargo, de aquí también se desprende una concepción sobre cuándo esa mujer debía "sentirse" madre, ligada al momento del nacimiento, y no a la gestación, una distancia con las concepciones contemporáneas acerca de la vida del feto y del supuesto sentimiento maternal.

Inmediatamente después de sancionado el Código, comenzaron las críticas con respecto a los fundamentos y las penas del mismo que provinieron, mayoritariamente, de los juristas y criminólogos de la escuela positivista. ${ }^{10}$ Las ideas introducidas por el positivismo redireccionaron muchos de los debates en materia penal. En 1890, el Poder Ejecutivo ordenó la creación de una comisión para reformar el Código de $1886 .{ }^{11}$ En 1900, se discutió en Diputados y, por primera vez, se cuestionó la exclusión de las mujeres a las penas. En un contexto profundamente marcado por el debate sobre la permanencia o no de la pena de muerte en la legislación, el diputado Carlos Olivera señaló que la discrepancia en la penalidad debía radicar en los actos de las personas y no en el sexo. Sin embargo, lejos estuvo de plantear una postura progresista en cuanto a la desigualdad de género, sino que consideró que la legislación establecía una diferencia basada en un ideal de mujer que distaba de las que delinquían, a las que consideraba "monstruos". Éstas atentaban contra las características femeninas "naturalmente" atribuidas: sensibilidad, piedad, compasión y amor materno, y, especialmente las que cometieron aborto e infanticidio, pusieron en cuestión este modelo doméstico maternal. Sin embargo, el diputado prosiguió y excluyó a las infanticidas de esa categoría debido a su condición y al móvil del delito y postuló que:

Propongo que se extienda la penalidad de la muerte a la mujer monstruo, es decir, al delincuente extraordinario (...) Pero si mañana el juez, se encontrare delante de una mujer débil que hubiera delinquido, que hubiera, por ejemplo, asesinado a su hijo recién

10. Véase: Baratta (1986) y Sozzo (2011, pp. 3-4).

11. Los integrantes de la comisión fueron los doctores Norberto Piñero, Rodolfo Rivarola y José Nicolás Matienzo, todos miembros de la Sociedad de Antropología Jurídica y adherentes del positivismo criminológico en Argentina. 
nacido por conservar lo que el mundo llama honor, por conservar la reputación, que forma parte de los intereses humanos, y sintiera incomodidad y mortificación porque la ley le facultara para imponer la represión máxima a ese delincuente, no haría más que reflejar los sentimientos de la sociedad en que vivimos. Pero si se encontrare frente a un monstruo real, de un caso de extraordinario de delincuencia ¿por qué habría de retroceder? ${ }^{12}$

En este sentido, si la mujer era naturalmente un ser débil y sensible, el cometer un delito las desnaturalizaba dejando a la vista el carácter social que revestía la domesticidad y la maternidad, al punto de considerarla un "monstruo". Estas ideas, como señala Michel Foucault (2007), refieren a la construcción del individuo anormal, "monstruo (...) es esencialmente una noción jurídica-biológica” que, desde comienzos del siglo XIX, afectó a los comportamientos e inició la condena de la "conducta monstruosa" o "criminalidad monstruosa". El "monstruo moral" indicaba "la sospecha sistemática de monstruosidad en el fondo de toda criminalidad" (pp. 77 y 79).

Si bien algunos diputados coincidieron con el planteo de Olivera, la mayoría de ellos reconocieron que éste retrocedía en cuanto a la pena aún más que la codificación de Tejedor. El diputado Juan A. Argerich argumentó que la verdadera razón de excluir a las mujeres de la ejecución era la maternidad, es decir, su carácter potencial de madres; a lo que Olivera excusó que esa maternidad era distinta a la de la "mujer monstruo", ya que ésta "engen-

12. Cámara de Diputados. Diario de

Sesiones (CDDS), 5 de septiembre de 1900,

p. 1149 -1150. Biblioteca del Congreso de

la Nación Argentina (BCNA), Cámara de

Diputados, Buenos Aires.

108 dra monstruos" y, por esto, también, debe ser ejecutada. Esta moción fue rechazada por la mayoría de los diputados, que dejaron entrever la emergencia de algunas tensiones que tomarán forma en el período siguiente acerca de la reproducción y la protección estatal de las madres con fines natalistas. Aunque el proyecto de 1891 no era de reforma total y no fue aprobado, algunos de los cambios propuestos se introdujeron mediante la ley 4.189 de 1903. Esta ley aumentó el promedio de las penas en general y, con ello, las de aborto e infanticidio. ${ }^{13}$

Asimismo, el infanticidio incorporó una modificación sustancial al admitir, además de los abuelos maternos, a los padres, hermanos, marido e hijos como posibles infanticidas. De esta manera, la nueva ley consideró que no sólo era la mujer y sus padres quienes podían reponer su honra frente al nacimiento ilegítimo, sino que esta consideración fue extendida hacia otros varones. La justicia supuso que les afectaba directamente, al punto de disminuirles la pena de ejecución por homicidio agravado por el vínculo. Inmediatamente, emergieron voces críticas a esa norma. En 1916, el diputado Rodolfo Moreno presentó en la Cámara un proyecto de ley que reproducía, con pocos cambios, el de la comisión.

En los proyectos de 1906 y 1916, sólo tuvieron mínimas modificaciones en relación a la pena el castigo para el delito del aborto y del infanticidio. ${ }^{14}$ En este momento de definiciones y redefiniciones, el análisis de los debates $\mathrm{y}$ tensiones sobre los delitos de aborto e infanticidio nos permiten ahondar en el proceso de construcción de las normas en relación a la sexualidad, reproducción y maternidad. El or-

13. Véase anexo.

14. Véase anexo. 
den patriarcal operó buscando controlar la esfera de la sexualidad, así se definió como delito propiamente femenino el aborto y el infanticidio. Las madres solteras se convirtieron en sujetos potencialmente peligrosos para el orden social patriarcal ya que pusieron en cuestión la naturalidad establecida en el binomio madre- hijo dentro del marco del matrimonio. Al mismo tiempo, las consideraciones acerca de la mujer como un ser virtuoso, débil y sensible se contrapusieron con las de aquellas que delinquían; construyéndose un doble discurso ligado a la delincuencia femenina que osciló entre el discurso antinatural y los delitos "tipo de su género", como el aborto y el infanticidio. De esta manera, la honra se transformó en un elemento central del discurso jurídico de fines del siglo XIX para fundamentar las prácticas de aborto e infanticidio y fue el único motivo posible para justificar que una madre se deshiciera de su hijo y, por ende, el único móvil legalmente válido para que el crimen fuera atenuado.

\section{Tensiones entre eugenesia y honor en los debates jurídico- legislativos} (1921-1941)

El último intento de sanción del proyecto de 1891 tuvo lugar en el año 1900, cuando la comisión de códigos de la Cámara de Diputados propuso un nuevo proyecto de ley de reformas. Aunque éste no fue aprobado influiría notoriamente en el siguiente proyecto que fue presentado, en 1906, por Rodolfo Moreno (hijo). El proyecto pasó su primera instancia de debate legislativo en el año 1917, en la cámara de Diputados, donde el aborto y el infanticidio no fueron modificados. Sin embargo, ante su llegada a la Cámara de Senadores, en 1920, se suscitaron profundos cambios que se mantuvieron intactos durante el período analizado y que relucen las tensiones subyacentes en la legislación penal de 1921 sobre maternidad y género. Este momento constituye un punto de inflexión en nuestro estudio por dos motivos. Por un lado, porque este Código se mantiene vigente hasta el presente, luego de, como veremos más adelante, diversas reformas. Por otro lado, porque en el caso del aborto, incluyó por primera vez dos atenuantes que definieron las situaciones en que la práctica no es punible y para el infanticidio incluyó el estado puerperal y la emoción violenta, como dos condicionantes de la figura que produjeron que sólo una reducida cantidad de casos sean en clasificados como tales.

Con respecto al infanticidio, basándose en el anteproyecto del código, la Cámara de Senadores introdujo dos modificaciones. En primer lugar, y luego de establecer una división entre lo que se consideraba "delincuencia típica", "media y grave" y "delincuencia atípica", con prisión de 6 meses a 2 años, 3 a 25 años y tiempo indeterminado, respectivamente, redujo notablemente la pena para el infanticidio. El infanticidio fue considerado "delincuencia típica" y redujo la pena de 3 a 6 años propuesta en los proyectos y aprobada en diputados, a 1 a 3 años de reclusión o 6 meses a 2 años de prisión. En segundo lugar, consideró que en relación con la muerte del recién nacido no debía establecerse un período inamovible de 3 días, sino que debía contemplarse la particularidad del hecho mientras durase el estado puerperal de la madre. ${ }^{15} \mathrm{El}$ estado puerperal era discutido principalmente para los casos de infanti-

15. Cámara de Senadores. Diario de Sesiones (CSDS), 23 de septiembre de 1920, p. 957. BCNA, Buenos Aires. 
cidio: ya no se consideraba que el honor por sí mismo podía forzar a la mujer a deshacerse de su hijo, sino que para que eso ocurriese la madre debía estar, además, bajo la influencia del estado puerperal. En este sentido, la motivación del honor tuvo que ser reforzada con otra explicación, de amplia circulación en las revistas jurídicas de la época, que refería a la alteración histérica que le producía a la mujer el post parto. ${ }^{16}$

En cuanto al honor vincular, introdujo una restricción en el lazo familiar de la delincuente y propuso que la reducción en la pena sólo sería extensible a los padres, hermanos, marido e hijos de la madre, siempre y cuando éstos estuvieran en un estado de emoción violenta que debía estar estrictamente comprobado. Máximo Sozzo (2015), al estudiar el nacimiento de la intersección entre el dispositivo penal y el dispositivo alienista/psiquiátrico en Argentina, ha propuesto que el paso a la racionalidad penal moderna comenzó incipientemente en la segunda mitad del siglo XIX y, a través de sutiles cambios, logró consolidarse en el campo jurídico criminal. Para el infanticidio $\mathrm{y}$ aborto, estas tensiones que se inauguraron con el primer código penal, fueron debatidas e incorporadas lentamente a través de la doctrina y jurisprudencia, así produjeron desplazamientos que se cristalizaron en la sanción del Código de 1921, en un contexto de creciente interés por parte del estado en el control de la maternidad y la crianza de la niñez.

16. El histerismo fue un tema recurrente en las revistas criminológicas de la época para explicar la delincuencia femenina. Dentro de esta categoría, el estado puerperal fue elemento más abordado para explicar los comportamientos de las mujeres, especialmente de las infanticidas.

110
Sin embargo, el aborto fue penado más duramente que el infanticidio, al mismo tiempo que recibió una modificación sustancial, inexistentes desde el proyecto de 1891. Al mismo tiempo, aumentó la pena a la mujer que causare su aborto. ${ }^{17}$ Así, y sin modificaciones en Diputados, llegó a la Cámara de Senadores, la cual no disminuyó su penalidad, es decir, que no lo consideró un delito típico al igual que el infanticidio, ni que la deshonra podía modificar su penalidad, sino que fue enmarcado dentro de los delitos de peligrosidad media. Sin embargo, incorporaron dos incisos para abortos no punibles en caso de que hubiera peligro para la vida o salud de la madre o si el embarazo proviniera de una violación sobre la mujer idiota, demente, inconsciente o de incesto. Aquí, la intertextualidad con el discurso médico eugenésico es manifiesta. ${ }^{18}$

La comisión, formada por los senadores Joaquín V. González, Enrique del Valle Iberlucea y Pedro A. Garro, fundamentó la incorporación de la no punibilidad de los abortos con fines terapéuticos y eugenésicos, a partir del ejemplo del anteproyecto Código suizo (art. 112) que fue considerado por los juristas como una verdadera superación e innovación en materia legislativa. En el informe, las razones que se esgrimían para argumentar el primer inciso (aborto terapéutico), decían, no tenía más explicación que "cuando el aborto es indispensable para la salud o la vida de la madre, no constituye delito". Sobre el segundo inciso, los senadores utilizaron las palabras del reconocido jurista Luis Jiménez de Asúa, para referirse al carácter innovador del anteproyecto suizo, "Es la primera vez que una legislación va a atreverse a legislar el aborto con un fin

17. Véase anexo.

18. Véase anexo. 
eugenésico, para evitar que, de una mujer idiota o enajenada, o de un incesto, nazca un ser anormal o degenerado (...) ¿Qué puede resultar de bueno de una mujer demente o cretina?". Adhiriendo a estas ideas, los miembros de la comisión señalaban que "es indiscutible que la ley debe consentir el aborto cuando es practicado con intervención facultativa, a los fines del perfeccionamiento de la raza". Este problema, decían, se planteó en Europa cuando, durante la guerra, muchas belgas fueron violadas por soldados "ebrios, desenfrenados o criminales". ${ }^{19}$

Si bien la aprobación final de las reformas al Código Penal restringió las posibilidades de abortos no punibles a los casos de violación de una mujer "demente" o "idiota", la cuestión generó debates hasta la actualidad.

La incorporación del estado puerperal para el infanticidio y la creación del aborto con fines terapéuticos y eugenésicos, como figura no punible del código penal, respondieron a lógicas contradictorias, una de carácter modernizador -en aquel contexto- y otra de corte tradicional, que convivieron en la codificación penal moderna en relación al control de las sexualidades y la reproducción. Por un lado, la honra siguió justificando el móvil para los casos de infanticidio al mismo tiempo que se incorporó el estado puerperal y la emoción violenta como requisitos de la misma figura. Por otra parte, la inclusión de abortos no punibles, respondió a la preocupación por la "calidad" de la población a partir de la creciente influencia de la eugenesia en el ámbito local, particularmente en el campo médico. Estas tensiones, también,

19. CDDS, 23 de septiembre de 1920, González, J. V., Del Valle Iberlucea, E. y Garro, P. A. Informe de la Comisión de Códigos, pp. 937-960. BCNA, Buenos Aires. responden al proceso de medicalización de la reproducción iniciado a fines de siglo XIX que ubicó a los galenos como los únicos agentes legítimos de intervenir en el embarazo y el parto, deslegitimando y penalizando el trabajo de las parteras y comadronas, quienes, también, eran quienes realizaban los abortos (Nari, 2004). En este contexto, los representantes de la elite médica apoyaron estas medidas que les otorgaban un papel central. Por ejemplo, para el obstetra Josué Beruti, docente de la Facultad de Ciencias Médicas de la Universidad de Buenos Aires, el problema con relación al aborto se presentaba cuando era producto de un acto voluntario, al que se catalogaba como "aborto provocado criminal". Su práctica, junto con "el aumento de mujeres solteras, matrimonios tardíos, enfermedades esterilizantes, prácticas neomalthusianas", resultaban, para el galeno, la causa de la baja en la tasa de natalidad (Beruti y Iraeta, 1922). ${ }^{20}$

Los delitos de aborto e infanticidio sufrieron importantes modificaciones con la reforma del Código en 1921 que puede considerarse como un momento bisagra en la codificación penal. Las modificaciones realizadas concentraron debates existentes desde la sanción del Código de 1886, inaugurando una nueva etapa en materia penal en Argentina. Sin embargo, luego de su sanción, emergieron importantes proyectos de reforma como el de Eduardo Coll y Eusebio Gómez (1937) y el de Peco (1941).

En septiembre del año 1936, el presidente Agustín P. Justo designó a Coll y a Gómez como redactores de un nuevo proyecto de Código, presentado un año después. $\mathrm{El}$ proyecto trató al Código de 1921 y se propuso realizar modificaciones con el objetivo de modernizar

20. Véase también Beruti (1943, p. 528). 
el Código vigente, las cuales Zaffaroni y Arnedo (1996) caracterizaron como positivistas por la orientación de los autores hacia la teoría de la peligrosidad y defensa social. El proyecto se constituyó sobre tres pilares: la contemplación de los problemas sociales que incitaban a la delincuencia, los factores de carácter psicológicos y el principio de peligrosidad basado en rigurosos estudios científicos.

La fundamentación del proyecto dejó relucir las tensiones entre el campo jurídico y el legislativo, haciendo referencia al carácter modernizador de las comisiones integrada por juristas y los frenos del legislativo al respecto. Según Coll y Gómez, las ideas de los juristas que elaboraron la codificación penal antes de 1921 acerca del derecho aspiraban al progreso, el problema se encontraba en los debates parlamentarios que, según los autores, desoían el trabajo realizado por las comisiones técnicas. Esta aclaración de parte de los autores deja entrever un problema entre las interpretaciones jurídicas de las comisiones y la legislatura que se mantendrá presente durante todo el período.

Para los casos de infanticidio, señalaron una crítica con respecto a la redacción del código vigente por ser confusa a la hora de su interpretación y no estar redactada en términos certeros. Sin embargo, para Coll y Gómez, la referencia al infanticidio en el Código Penal a "o en estado puerperal" se podía prestar a discusiones ya que no se entendía bien si es la madre que mata a su hijo para ocultar la deshonra o bajo el estado puerperal. En este sentido, reafirmaron que el único móvil del infanticidio era el ocultamiento de la deshonra por la madre ilegítimamente fecundada (y familiares) y éste tenía que ser el único propósito por el cual se realizara el hecho. En este sentido, ni la honra ni el estado puerperal podían fundamentar por sí mismos que una madre matara a su hijo, la explicación precisó reforzar estos dos componentes para casos que representaron los delitos contra la maternidad por antonomasia. Asimismo, postularon que el infanticidio requería una cronología para el estado puerperal que, a su vez, debía comprobarse fehacientemente.

En relación con el aborto, el proyecto propuso modificaciones de vanguardia en materia jurídica. Por un lado, plantearon atenuar la pena al mínimum para la mujer que -por ocultar su deshonra- causare su propio aborto o aceptara que otro lo realice, al igual que en los infanticidios y abandono de recién nacidos. Por otro, propusieron modificar la figura de "aborto terapéutico" por "aborto autorizado", dejando de manifiesto la superación de las ideas meramente eugénicas sobre el aborto no punible. Esta figura se ampliaba a las mujeres que autorizaban a un médico diplomado a practicarles un aborto cuando el embarazo provenía de una violación. ${ }^{21}$

Las sugerencias en cuanto a las consideraciones sobre la honra como el único móvil para el infanticidio o su incorporación como atenuante que disminuía la pena para el delito de aborto, deben analizarse teniendo en cuenta el contexto de locución discursiva. Durante los años veinte y treinta, los discursos maternalistas eran un horizonte de sentido para diversos posicionamientos ideológicos. Así, por ejemplo, las consideraciones sobre la madre soltera comenzaron a modificarse y algunos sectores dirigentes de la sociedad exigieron una legislación que las salvaguardara (Ledesma Prietto,

21. Véase anexo. 
2015). ${ }^{22}$ Como señala Marcela Nari (2004), las propuestas médicas oficiales hacia las "madres solteras" no se traducían en nuevas consideraciones sobre la mujer y su libertad sexual, sino que respondían a otras lógicas. Por un lado, se consideraba que "por su inocencia o por su profundo amor a un hombre, había sido objeto de seducción, de engaño y de abandono". Por otro lado, la preocupación por la salud de la población, las hacía objeto de la mirada médica (p. 140). Este discurso médico, que en la racionalidad jurídica logró permear a través del dispositivo alienista, impactó directamente en las consideraciones acerca del aborto y del infanticidio, incorporando el aborto terapéutico, en el caso del primero, y el estado puerperal y la emoción violenta, en el caso del segundo. Sin embargo, el móvil del honor no fue fácilmente desplazado, al contrario, fue un elemento que se mantuvo hasta que el infanticidio fue retirado del Código en 1994, transformándose en un bastión del discurso jurídico para explicar esta práctica pero que, al mismo tiempo, no bastó para ello y debió recurrirse a otras ideas de corte alienistas. En este sentido, la cuestión de la honra y el estado puerperal jugaron, durante esta etapa, un papel crucial dado que se convirtieron en la excusa para justificar la criminalidad femenina que reforzó y, al mismo tiempo, no se opuso, a los supuestos maternalistas. La cristalización de esta intersección en el campo de la reproducción y las sexualidades podemos observarla en los debates y en la sanción del código penal de 1921 sobre las figuras de aborto e infanticidio, donde claramente convivieron dos tendencias que, si bien pueden considerarse contradictorias, fueron

22. Por ejemplo, a las mujeres que no cumplieran con "el deber de amamantar a su hijo", o lo hicieran con uno ajeno antes que, con el propio, o no alcanzasen un período de amamantamiento de cinco meses, les corresponderían aquellas sanciones. complementarias y traccionaron hacia un discurso de maternalización y eugenesia que, por un lado, necesitaba de nuevos elementos para justificarse y, por otro, permitió el aborto en ciertos casos que le fueron funcionales para el "mejoramiento de la raza". Al mismo tiempo, conviven con otras perspectivas de carácter social, representadas por el proyecto de Coll y Gómez, que se verían reforzadas durante el período siguiente.

\section{Redefiniciones en torno a la criminalidad femenina: la consolidación del discurso social (1941-1968)}

En los años cuarenta del siglo XX, las preocupaciones por la denatalidad encontraron su momento culmine. Si bien el incremento de la natalidad fue uno de los atributos requeridos para la modernización del Estado, como señalan Carolina Biernat y Karina Ramacciotti (2013), los intereses poblacionistas estuvieron marcados por la oscilación entre estimular la población con flujos migratorios o con recursos humanos endógenos y entre aumentar la "cantidad" sin descuidar la "calidad" de la población.

En este clima de ideas, el 25 de septiembre de 1941, el jurista y diputado por la Unión Cívica Radical José Peco presentó un proyecto de Código Penal a la Cámara que recibió elogios de juristas de renombre como Jiménez de Asúa (Pinto Bouquet, 1942). Nos detenemos en el análisis de este proyecto dado que propuso reformas con nuevas miradas sobre el infanticidio y el aborto. De orientación neopositivista, como él mismo lo fundamentó, planteó la necesidad de establecer cambios basándose en el progreso de la ciencia, el derecho penal 
y la criminología. Asimismo, señaló el aumento del crimen y la reincidencia como prueba de lo incoherente e insuficiente que era, hasta entonces, la legislación penal. Buscó un equilibrio entre la defensa social y las garantías de libertad. En función de ello, las figuras de aborto e infanticidio fueron repensadas.

En torno al infanticidio, al igual que Coll y Gómez, señaló que el estado puerperal debía eliminarse como criterio para definir el delito, por su carácter de "vago, incierto y peligroso". Desde su incorporación al Código en 1921, el estado puerperal suscitó numerosas discusiones acerca de si se debería establecer un tiempo fijo o no. Como veremos, estas consideraciones también variaron en los proyectos de reforma. Sostenía que, aunque éste se produjera, seguía siendo necesario "el móvil ético del honor" (Peco, 1943). ${ }^{23}$ También, distinguía las penas entre la madre infanticida y las/os familiares que cometían el delito. Justificaba esta distinción en ideas maternalistas: la "desigualdad de la sanción se funda en la trágica situación de la madre que inmola el instinto de la maternidad en holocausto al honor". Explicaba, también, que la inclusión del esposo como infanticida, obedecía a "la tradición argentina" antes que al reflejo de una situación real. Además, indicaban que, si se diera el caso, su acción respondería a salvar su propio honor, antes que el de su esposa. Su fundamentación recogió un aspecto social mencionado durante los años anteriores, la madre engañada y abandonada por el hombre que la somete al deshonor y, por ende, al infanticidio. Es por esta situación, reconocida como uno de los motivos principales del delito, que Peco pretendió excluir al padre del recién nacido de los merecedores del atenuante y mantiene a los demás familiares, a

23. Véase también Zaffaroni y Arnedo (1996, p. 188). quien considera capaces de movilizarse verdaderamente por ocultar la deshonra de la mujer, y no únicamente la propia. En cuanto a las penas, proponía una sanción, acorde a esta nueva orientación neopositivista, que mediara entre un sistema riguroso y un sistema benigno. Para él, era inconcebible que el infanticidio tuviera menos pena que el aborto y el abandono de niños "a pesar de su mayor gravedad objetiva y de lastimar de manera subrayada el sentimiento de la maternidad" (Peco, 1943). ${ }^{24}$ Igualmente, reconocía que estas tres figuras delictivas eran "consecuencia de influencias sociales", así, discutía las ideas que explicaban la criminalidad femenina como un estado de desequilibrio mental (Peco, 1943). ${ }^{25}$ Sus propuestas sobre el aborto, al igual que las del proyecto de Coll y Gómez, fueron vanguardistas para el período; sin embargo, teniendo en cuenta sus fundamentaciones, podríamos decir que las ideas de Peco fueron aún más progresistas en las cuales se perciben una empatía mayor con las condiciones sociales de las mujeres, que antes no habían sido consideradas.

En primer lugar, entendía que el aborto no debía ser penalizado en dos situaciones precisas: si la mujer se lo autogestionaba o consentía la práctica. Sostenía que la sanción tenía una base moral antes que jurídica y que el aumento de las penas no se traducía en una disminución de los abortos. Sin embargo, reconocía que esta propuesta no tendría aceptación y, entonces, habría que continuar el camino trazado por la legislación penal desde el inicio del proceso codificador. Por ello, propuso entre las reformas una leve sanción para la mujer que consintiera o se practicara su propio aborto, de tres meses

24. Véase también Zaffaroni, Eugenio y Arnedo (1996, p. 191).

25. Véase también Zaffaroni y Arnedo (1996, p.193). 
a dos años. ${ }^{26}$ En segundo lugar, sostuvo, como el proyecto anterior, que el aborto en caso de violación no debía ser punible, al igual que en casos de incesto. Agregó, también, la cuestión del plazo, antes de los tres meses de embarazo. Esta cuestión fue y es muy discutida dada la ambigüedad del Código. Pero lo novedoso fueron las motivaciones de estas reformas. Sus justificaciones no devenían de cuestiones eugenésicas, sino en la defensa del derecho de las mujeres solteras o casadas a quienes la ley las obligaba, decía a "soportar una maternidad odiosa" (Peco, 1943). ${ }^{27}$ En este sentido, también incorporó la deshonra como atenuante de la pena, la cual quedaba a consideración del juez. Esta modificación incluía a los familiares al señalar a quienes quieran ocultar la deshonra de "la esposa, hija, hermana o madre" (Peco, 1943). ${ }^{28}$ Por último, entre las particularidades del proyecto de Peco el aumento de la pena en los casos en que la causa de un aborto produjera la muerte de la mujer cuando ella no lo consintiere. ${ }^{29}$ Este cambio, también, puede entenderse como una apuesta a los derechos de la mujer sobre su propio cuerpo, al penar con fuerza a quienes accionaran sobre él. Si bien, el proyecto del diputado no fue tratado, el estudio de sus ideas resulta interesante porque sería la primera vez que un proyecto de código contemplaría no sólo la condición social, abordada por Coll y Gómez, sino la voluntad personal de las mujeres en relación a la reproducción y la sexualidad.

La llegada del peronismo, como señala $\mathrm{Ra}^{-}$ macciotti (2006), en torno a la preocupación

26. Véase anexo.

27. Véase también Zaffaroni y Arnedo (1996, p. 195).

28. Véase también Zaffaroni y Arnedo (1996, p. 564).

29. Véase anexo. demográfica, dio continuidad y acentuó posturas presentes en la década del treinta y cuarenta a medida que la intervención estatal iba en aumento. Desde la historiografía, el estudio de las políticas públicas enunciadas e implementadas por el gobierno peronista dieron lugar a un debate sobre el carácter pronatalista-promaternalista de aquellas. Dora Barran$\cos (2008)$, en disonancia con estudios que han argumentado que el interés del gobierno fue aumentar la población sana y que en razón de ello la mujer tenía un rol central; indicó que "no puede confundirse "pro maternalismo» $-\mathrm{y}$ alguna retórica pro engendradora que emplean ciertos funcionarios del peronismo- con medidas políticas que impulsaron la obligación de parir durante esos años en los que el Estado tomó el color benefactor (p. 489). ${ }^{30}$ Ramacciotti y Adriana Valobra (2004), además de plantear la existencia del debate, incluyeron otra categoría: "políticas de crianza estatizada" e incorporaron en ella algunas de las políticas públicas del primer gobierno peronista donde convivían con las maternalistas. ${ }^{31}$ Las políticas de crianza estatizada las entendieron como las "que el Estado implementa para atender a la infancia desplazando temporal o completamente a la madre y a la célula familiar en general" (Valobra, 2005b, p. 81). En este sentido, Cosse (2004) señala que la niñez en el peronismo se resignificó y se volvió un pilar fundamental para el gobierno, pues "la vieja intención de convertir a los niños en ciudadanos capaces de contribuir al desarrollo nacional se trasladó a la necesidad de garantizar la continuidad de la «revolución» y la perpetuidad del régimen del poder" (p. 520). El análisis de los proyectos de reforma del Código Penal envia-

30. La autora debate, particularmente, con las ideas de $\mathrm{Di}$ Liscia (2000).

31. Véase también Valobra (2005a). 
dos al Congreso Nacional por el Poder Ejecutivo en 1951 y 1953 nos permiten realizar aportes a este debate.

La necesidad de incorporar modificaciones en el cuerpo legal, estaba vinculada, señalaba el proyecto del año 1951, con la incongruencia o incompatibilidad entre el espíritu de la Constitución Justicialista sancionada en 1949 y el Código vigente. Particularmente, se marcaba una nueva conceptualización del propósito de las penas sostenidas en la Constitución, la cual era "la reeducación social del delincuente, colocando así a la represión penal, o mejor dicho, a la defensa social, sobre un nuevo plano de trascendentes perspectivas y proyecciones" (Perón y Gache Pirán, 1951). ${ }^{32}$ Asimismo, contenía un apartado especial dedicado, decía "a coordinar las normas que regularán la reeducación social de los niño, adolescentes y jóvenes, en cuyas vidas se hubieren producido manifestaciones que indiquen la necesaria intervención del Estado para impedir la ulterior cristalización de una personalidad criminal”. Ello, sostenía el documento, en función del "carácter asistencial que inspira todo el Proyecto" (Zaffaroni y Arnedo, 1996, p. 12). Esta particular preocupación, abona las interpretaciones sobre el interés del gobierno en una mayor intervención sobre la niñez. En cuanto al infanticidio y el aborto, se enunciaban algunas modificaciones en torno a las penas y la definición de los tiempos. Para el infanticidio, la pena se establecía entre 3 y 10 años y se ampliaba el plazo, quedando a disposición del juez establecer las circunstancias del caso. En cuanto al delito de aborto, las penas aumentaban cuando la práctica era autogestionada o consentida. Esto se explicaba, según el proyecto, porque "en el ordenamiento civil vigente, el ser concebido es titular de de-

32.. Véase Zaffaroni y Arnedo (1996, p. 7). terminados derechos, lo que importa el reconocimiento de su personalidad jurídica" ( $\mathrm{Za}$ ffaroni y Arnedo, 1996, p. 13). Asimismo, se imputaba la tentativa de la mujer y se excluía de la no punibilidad el aborto eugenésico. Esta última y trascendental modificación se fundamentaba en que "la ley no puede conferir a terceros el erigirse en árbitros de la situación de otra persona, que puede afectar su vida, su salud o sus sentimientos" (Zaffaroni y Arnedo, 1996, p. 13). En suma, el proyecto de reforma del Código Penal de 1951, retrocedía a la legislación del siglo XIX en cuanto al infanticidio, pero, particularmente, en relación con el delito de aborto. Sobre esta última cuestión, aunque pueda interpretarse como un indicio de pro-natalismo o pro-maternalismo, la severidad contra los delitos vinculados a la reproducción, si los situamos en el conjunto de reformas vinculadas a dar especial atención a los menores; la desautorización de los médicos en la decisión de la práctica; la centralidad otorgada al ser concebido y por último, al definir el aborto como "la interrupción del embarazo, con la muerte del feto" (Zaffaroni y Arnedo, 1996, p. 82); nos resulta más pertinente la idea de "crianza estatizada". Dado que en ningún momento se menciona a la mujer o la defensa de los derechos de la mujer para tales reformas, sino que sólo se da entidad al "feto" o "ser concebido" es evidencia de la creciente intervención del gobierno sobre la infancia.

$\mathrm{Al}$ no ser tratado este proyecto, en 1953 se presenta otro, pero no retoma las apreciaciones del anterior. Escrito por Ricardo Levene (h), Horacio Maldonado y Francisco La Plaza, con el auspicio del Poder Ejecutivo, en líneas generales, establece el plazo del infanticidio hasta tres días después del nacimiento, disminuye la pena de uno a ocho años y vuelve a incluir el aborto no punible para el caso de violación y no pena 
su tentativa. En cuanto a los fundamentos del proyecto, se elaboraba en base a trabajos realizados por La Comisión de Legislación penal de la Cámara de Diputados sobre el proyecto del año 1951 y posteriores estudios del Poder Ejecutivo. Sin embargo, éste no fue tratado y, hasta el año 1960, no se presentó un nuevo proyecto de Código.

El presidente Arturo Frondizi, en 1958, encomendó la redacción al jurista Sebastián Soler, de un anteproyecto, presentado el 31 de marzo de 1960. En nuestro análisis, este documento resulta significativo dado que es la base para el Código Penal sancionado mediante una Ley de facto en el año 1968, límite de nuestro período de estudio por incorporar una reforma fundamental originada en la propuesta de Soler. En relación con el infanticidio, Soler (1960) propuso que la atenuación solo recaería en la madre y aumentó la pena apoyándose en los cambios producidos en la sociedad porque, sostenía, "modernamente es mucho menor la coacción de la deshonra derivada de tener un hijo fuera del matrimonio". ${ }^{33}$ Esta afirmación se enmarcaba en el cuestionamiento previo de la distinción jurídica entre hijos legítimos e ilegítimos. Particularmente, durante el peronismo, fueron tratados dos proyectos de reforma sobre la filiación y, finalmente, en 1954, se aprobó la ley 14.367 que redujo la catalogación tripartita (naturales, adulterinos e incestuosos) a la categoría binaria "hijos matrimoniales"/ "extramatrimoniales". Esta ley no incluyó igualación absoluta de derechos de todos los hijos y conservó como criterio de distinción entre los derechos de la descendencia a la institución matrimonial, debido a la ofensiva de la Iglesia Católica, pero sancionó una denominación menos peyorativa, elevó significativamente los

33. Véase también Zaffaroni y Arnedo (1996, p. 383). derechos de los, antes considerados, ilegítimos (Cosse, 2008b).

El proyecto de Soler incorporó el aborto honoris causa porque entendía que era una contradicción que estuviera presente en el delito de infanticidio y no en aquel, como ya lo había esbozado Peco. Su proyecto resultaba más ordenado que las anteriores y se orientaba a una mayor definición y especificación. Soler (1960) definió el aborto como "la muerte de un feto en el seno materno o mediante su expulsión prematura" y ordenó el articulado mediante subtítulos, tales como aborto con y sin consentimiento; aborto procurado; aborto por causa de honor; aborto impune y aborto preterintencional (p. 440). ${ }^{34} \mathrm{Al}$ igual que el proyecto de Coll-Gómez y Peco, Soler sostuvo la inimputabilidad del aborto en caso de violación. Luego de la presentación del anteproyecto, una Comisión Asesora, Consultiva y Revisora elevó un Informe que contenía modificaciones menores. Soler presentó el proyecto definitivo $\mathrm{y}$ una nota respondiendo a cada una de las sugerencias de la Comisión el 10 de noviembre de 1960. Desde ese momento, la Comisión de Legislación Penal de la Cámara de Diputados lo evaluó a partir de encuestas a distinguidos juristas (López Camelo y Jarque, 2004). El proceso de sanción del proyecto quedó trunco cuando el presidente José María Guido, luego del derrocamiento de Frondizi, suspendió la actividad parlamentaria.

Los años sesenta presentan algunas características que evidencian las tensiones y debates en torno a la sexualidad, la reproducción y la maternidad. Según Karina Felitti (2012), en estos años "cobraron visibilidad nuevos modelos de relación entre varones y mujeres, cambios en

34. Véase anexo. 
las configuraciones y vínculos familiares y pautas más abiertas en términos de moral sexual" (p. 11).

Para contrarrestar el efecto que podrían tener estos cambios, pero atendiendo al papel de la mujer en el mercado laboral, bajo la presidencia de Frondizi se crea la Dirección Nacional de Seguridad y Protección Social de la Mujer dentro del Ministerio de Trabajo y Seguridad Social. Ésta se propuso cumplir la "ley de maternidad y ajustar sus contenidos económicos a las nuevas condiciones de inflación”. Pero también, señala Felitti (2012), "se propuso garantizar la <dignidad> del trabajo femenino, evitando que las tareas de la mujer fuera del hogar pusieran en jaque la institución familiar" (pp. 61-62). El análisis de las políticas orientadas a la maternidad durante el período contribuye a desmontar qué modelos de feminidad se promovían desde el Estado a fin de legitimar el papel de las mujeres en la escena pública pero dentro de ciertos parámetros que no corroyeran ni la familia ni los roles tradicionales.

El gobierno militar que se instauró luego del Golpe de Estado, en 1966, propuso una serie de medidas que beneficiaban a las mujeres. Por ejemplo, la creación de la Caja de Subsidios y Asignaciones Familiares y la Ley 17.711 que determinó "la plena capacidad de las mujeres cualquiera fuera su estado civil" afectó positivamente los derechos civiles de las mujeres. $\mathrm{El}$ análisis de estas medidas permite sostener a Felitti (2012) que "reflejaron concluyentemente el afán modernizador del gobierno y demostraron cómo una dictadura militar autoproclamada conservadora y de características ciertamente reaccionarias pudo terminar favoreciendo a las mujeres en algunos aspectos" (pp. 64-65). En este sentido, coincide con las ideas planteadas por Mala Htun (2003), lue- go corroboradas por los trabajos de Verónica Giordano (2012) sobre lo paradójico de que muchas normas "liberadoras" de las mujeres, se produjeron en contextos autoritarios. En este sentido, las modificaciones en el Código Penal también se ubican en este plano, al menos, para el caso del delito de aborto.

El gobierno de facto, inmediatamente después de tomar el poder, encomendó a una Comisión formada por Soler, Carlos Fontán Balestra y Eduardo Aguirre Obarrio la elaboración de una reforma integral de la legislación penal", quienes entregaron el proyecto a fines de 1967 (López Camelo y Jarque, 2004, p. 52). Esta ley de facto 17.567, sancionó las reformas del Código, las cuales entraron en vigencia en abril de 1968. Las modificaciones vinculadas al infanticidio son dos; una, el aumento de la pena; y otra, exclusión de los familiares en la figura. ${ }^{35}$ La comisión sostuvo que los cambios se fundamentaban en las transformaciones sociales sucedidas desde la sanción del Código Penal vigente "en cuanto a la censura y aun el repudio que la maternidad irregular acarreaba. De dicho cambio es fuerza deducir que este homicidio es hoy mucho menos excusable y que en ningún caso debe serlo por terceros". ${ }^{36}$ Este ese sentido, podemos pensar que aquella intersección entre el dispositivo alienista y el penal que caracterizó a la primera mitad del siglo $\mathrm{XX}$ en materia penal y que se cristalizó en la elaboración del Código de 1921, se resquebrajaba. La emoción violenta que excusaba a los familiares de la infanticida, ya no era suficiente para atenuar el homicidio de un recién nacido, pero sí justificaba a la madre porque el repudio

\section{Véase anexo.}

36. Ley 17.567. 12 de enero de 1968. Boletín Oficial de la República Argentina. Véase también Zaffaroni y Arnedo (1996, p. 65). 
y la vergüenza social aún eran significantes. De igual modo, el aborto no punible sufrió dos cambios: se agregó la consideración de "grave" al peligro para la vida de la madre y se dispuso, a razón de que no haya confusiones, -señaló la Comisión- que el aborto no era punible en caso de violación y la acción penal se haya iniciado. Estas modificaciones, al menos en los motivos, no se fundamentaban explícitamente en la protección de los derechos de las mujeres, sino que se puede inferir, devienen de los cambios producidos en torno las conceptualizaciones de la sexualidad y la maternidad, particularmente, durante el período; que oscilaron en cuanto a la posición de las mujeres frente al Derecho Penal. Durante esta última etapa, los debates legislativos, fundamentalmente, entre la significación del honor como causa honoris del infanticidio y el aborto. Estas tensiones impactaron en los proyectos que, en reiteradas ocasiones intentaron introducir este atenuante para el aborto, pero que al llegar al legislativo se topó con una gran resistencia.

\section{Consideraciones finales}

En este trabajo nos propusimos ahondar en el análisis de la legislación penal respecto de dos delitos, el infanticidio y el aborto teniendo en cuenta dos claves de interpretación; los procesos modernizadores y las relaciones de género. A lo largo del estudio, nos interesó evidenciar cómo la perspectiva de género nos permite abordar la legislación penal con nuevas herramientas que posibilitan tensionar las intenciones modernizadoras y conservadoras en torno a la sexualidad, la reproducción y la delincuencia femenina. Para ello, en una mirada panorámica, distinguimos tres momentos para analizar aquellas intenciones y su comparación posibilitó indicar rupturas y continuidades en torno a los delitos bajo estudio.

El primer momento se caracterizó por inaugurar una nueva etapa en la historia del derecho penal a través de la codificación y, en tanto herramienta de control, construyó nuevas formas de abordar el infanticidio y el aborto. La voluntad humanista de la disminución de las penas convivió con antiguas nociones provenientes de la moral católica que se reflejaron en los delitos abordados en nuestro estudio. En el caso del aborto y el infanticidio disminuyó notablemente las penas e incorporó, para este último, la honra como móvil del delito. En este sentido, se podría pensar que la honra fue entendida, en este contexto, como un elemento modernizador. Empero, no fue incorporada para el aborto. Los sucesivos proyectos de reforma y los debates parlamentarios del período evidencian las tensiones en torno a la construcción de la mujer delincuente y la contradicción que representaba su práctica con el discurso de la domesticidad y el sentimiento innato por la maternidad. Para sortear las paradojas, aquella, fue interpretada como alguien anormal, un monstruo y la honra se convirtió en el único atenuante legal para que el crimen sea perdonado.

Un segundo momento, que dio comienzo con el Código Penal de 1921 cuando la intersección entre el dispositivo alienista, patriarcal y penal impactaron en las modificaciones realizadas en los dos delitos que abordamos. En el caso del infanticidio, se incorporó el estado puerperal como condición necesaria en la madre y la emoción violenta en el caso de los familiares directos de ella, pero, al mismo tiempo, el móvil del delito continuó siendo el ocultamiento de la deshonra. En el caso del 
aborto, aquella intersección se observa aún más claramente debido a que se incorporó la figura de aborto no punible. Asimismo, los médicos se erigieron como la única autoridad con el poder de intervenir en la realización de los abortos con fines terapéuticos o eugenésicos, deslegitimando y situando en la clandestinidad las prácticas de las parteras.

En el último momento, la justificación del honor y los discursos eugénicos y alinienistas, comenzarán a dialogar con otros de corte social que se expresarán más claramente en los años siguientes con los proyectos de Peco y, principalmente, el de Soler.

Por último, la ley de facto de 1968 fue aprobada por decreto e incluyó el aborto no punible para los casos de violación y eliminó a los familiares directos como posibles perpetradores de infanticidio. Esta vez, sin discusión legislativa y en el marco de un gobierno militar, las modificaciones fueron más progresistas en cuanto a los derechos sexuales y reproductivos de las mujeres.

En suma, en este recorrido intentamos poner de relieve las tensiones, contradicciones, rupturas y continuidades que se presentan en el largo plazo en relación con las consideraciones sobre el aborto y el infanticidio como delitos que atentaban contra la reproducción, el mandato maternal y virginal de las mujeres para dar cuenta, como mencionamos, cómo las construcciones culturales en torno al género han permeado y permean en la conformación de la legislación penal.

$$
\propto \tilde{e} \propto
$$




\section{Anexo \\ Cuadro 3. Aborto e Infanticidio en el Código Penal, modificaciones y proyectos de reforma (Argentina, 1886-1968)}

Código de 1886

Art. 100. La madre que por ocultar su deshonra cometiese infanticidio sobre la persona de su hijo, en el momento de su nacimiento o hasta

Definición tres días después, y a los abuelos maternos, que por ocultar la deshonra de la madre, cometiesen el mismo delito. Fuera de estos casos, el que cometiera infanticidio, será castigado con la pena del homicidio
Reforma 1903 (basada en el proyecto de reforma de 1891)

Art. 112 A la madre que, para ocultar su deshonra, matare a su hijo durante el nacimiento o hasta tres días después, y a los padres, hermanos, marido e hijos, que para ocultar la deshonra de su hija, hermana, esposa o madre, cometieran el mismo delito

\begin{tabular}{|c|c|c|}
\hline Pena & Penitenciaría de 3 a 6 años & Penitenciaria de 3 a 10 años \\
\hline Definición & $\begin{array}{l}\text { El que maliciosamente causare un aborto será } \\
\text { castigado } 1 \text { - Con penitenciaría de } 3 \text { a } 6 \text { años, si } \\
\text { ejerciere sobre la mujer embarazada; } 2 \text { - Con pri- } \\
\text { sión de } 2 \text { a } 3 \text { años si, aunque no ejerza violencia, } \\
\text { obrare sin consentimiento de la mujer; } 3 \text { - Con } \\
\text { prisión de } 1 \text { a } 2 \text { años, si la mujer lo consintiese". } \\
\text { Y aclaró en su artículo } 104 \text { que "la mujer que } \\
\text { violentamente causara su aborto o consintiere } \\
\text { que otra persona de lo cause, será castigada con } \\
1 \text { a } 3 \text { años de prisión, y si lo hiciera por ocul- } \\
\text { tar su deshonra, con el mínimum de esta pena". } \\
\text { Asimismo, en sus artículos } 105 \text { y } 106 \text { determi- } \\
\text { nó, respectivamente, que "los médicos, cirujanos } \\
\text { parteras o farmacéuticos que hicieran abuso de } \\
\text { su ciencia para causar aborto serán castigados } \\
\text { con penitenciaría de tres a seis años e inhabilita- } \\
\text { ción por doble de tiempo" y cuando "los medios } \\
\text { empleados causaren la muerte de la mujer se } \\
\text { aplicará el máximum de la pena }\end{array}$ & $\begin{array}{l}\text { Pena de tres a diez años de penitenciaría } \\
\text { al que causare aborto sin consentimiento } \\
\text { de la mujer y aumentó a quince años si el } \\
\text { hecho fuese seguido con su muerte; y de } \\
\text { uno a cuatro años de penitenciaría a quien } \\
\text { lo causare con su consentimiento y de dos } \\
\text { a seis años si causare su muerte. Al mismo } \\
\text { tiempo, aumentó la pena a la mujer que } \\
\text { causare su aborto se la reprimió con un año } \\
\text { a cuatro años de penitenciaría. }\end{array}$ \\
\hline Pena -para la mujer- & Art. 104. Prisión 1 a 3 años & Peniteciaría de 2 a 4 años \\
\hline
\end{tabular}


Art. 81 Inciso 2. A la madre que, por ocultar su deshonra, matare a su hijo durante el nacimiento o mientras se encontrara bajo la influencia del estado puerperal y a los padres, hermanos, marido e hijos que para ocultar la deshonra de la hija, hermana, esposa o madre, cometiesen el mismo delito en las circunstancias indicadas en la letra a) del inciso $1^{\circ}$ de este artículo: [Al que matare a otro, encontrándose en un estado de emoción violenta y que las circunstancias hicieran excusables].
Art. 118. A la madre que, por ocultar la deshonra, matare a su hijo durante el nacimiento o mientras dure su estado puerperal; y a los padres, hermanos, marido e hijos que cometieran el mismo delito obedeciendo idéntico móvil, si se encontraren en las circuntancias previstas en el inciso 1 del artóculo anterior (al que cometiere el delito en estado de emoción violenta que las circunstancias hicieran excusable).

\begin{tabular}{|c|c|c|}
\hline Pena & Reclusión hasta 3 años o prisión de 6 meses a 2 años & Prisión de 1 a 6 años \\
\hline Definición & $\begin{array}{l}\text { Art. } 85 \text {. El que causare un aborto será reprimido: } 1 \text { - Con } \\
\text { reclusión o prisión de } 1 \text { a } 3 \text { años si obrare sin consenti- } \\
\text { miento de la mujer. Esta pena podrá elevarse hasta } 15 \\
\text { años si el hecho fuere seguido de la muerte de la mujer. } \\
\text { 2- Con prisión o reclusión de } 1 \text { a } 4 \text { años si obrare con el } \\
\text { consentimiento de la mujer. El máximum de la pena se } \\
\text { elevará a } 6 \text { años si el hecho fuere seguido de la muerte de } \\
\text { la mujer. Art. } 86 \text {. Incurrirán en las penas establecidas en } \\
\text { el art. anterior y sufrirán, además, inhabilitación especial } \\
\text { por doble tiempo de la condena, los médicos, cirujanos, } \\
\text { parteras o fermaceuticos que abusaren de su ciencia o } \\
\text { arte patra causar el aborto o cooperasen para causarlo. El } \\
\text { aborto practicado por un médico diplomada con el con- } \\
\text { sentimiento de la mujer en cinta no es punible: } 1 \text { - Si se ha } \\
\text { hecho con el fin de evitar un peligro para la vida o la salud } \\
\text { de la madre y si este peligro no puede ser evitado por } \\
\text { otros medios. } 2-\text { Si el embarazo proviene de una viola- } \\
\text { ción o de un atentado al pudor cometido sobre una mujer } \\
\text { idiota o demente. En este caso el consentimiento de su } \\
\text { representante legal deberá ser requerido para el aborto. } \\
\text { Art. } 87 \text {. Será reprimido con prisión de } 6 \text { meses a } 2 \text { años, } \\
\text { el que con violencia causare un aboto sin haber tendio } \\
\text { propósito de causarlo, si el estado de embarazo de la pa- } \\
\text { ciente fuere notorio o lo constare. Art. } 88 \text {.Será reprimido } \\
\text { con prisión de } 1 \text { a } 4 \text { años, la mujer que causare su propio } \\
\text { aborto o consintiere a que otro lo causare }\end{array}$ & $\begin{array}{l}\text { Art. } 122 \text {. A la mujer que causare su pro- } \\
\text { pio aborto o consintiere que alguien lo } \\
\text { causare. Cuando el hecho respondiere } \\
\text { al propósito de ocultar la deshonra la } \\
\text { sanción será prinsión de } 2 \text { meses a } 6 \\
\text { años. A la simple tentativa de la mujer } \\
\text { no corresponde sanción alguna. } \\
\text { Art. } 125 \text {. Aborto autorizado: No dará } \\
\text { lugar a sanción alguna el aborto que } \\
\text { practique un médico diplomado, con } \\
\text { el consentimiento de la mujer o su re- } \\
\text { presentante legal, cuando el embarazo } \\
\text { proviene de una violación. }\end{array}$ \\
\hline $\begin{array}{l}\text { Pena -para la } \\
\text { mujer- }\end{array}$ & Art. 88. Prisión de 1 a 4 años, & $\begin{array}{l}\text { Art. 122. Prisión de } 1 \text { a } 4 \text { años y de } 6 \\
\text { meses a dos años (por deshonra) }\end{array}$ \\
\hline
\end{tabular}




\section{Proyecto del Poder Ejecutivo Perón-Gaché Pirán (1951)}

Proyecto de Levene, Maldonado y La Plaza con el auspicio del Poder Ejecutivo (1953)

Art.138. A la mujer que, para ocultar su deshonra matare a su hijo durante el nacimiento o hasta tres días después del parto

prisión de 1 a 8 años

Pena prisión de 2 a 10 años prisión de 1 a 8 años

Aborto sin consentimiento. Art.174. Al que, sin consentimiento de la mujer, provocare la interrupción del embarazo, con muerte del feto. Aborto consentido. Art. 175. Al que con consentimiento de la mujer, provocare el aborto. Aborto calificado por el resultado. Art. 176 en caso de muerte 178. lesiones graves o gravísimas. Aborto provocado por la mujer. Art. 178. A la mujer que provocare su propio aborto o lo consintiere. Aborto por causa del honor. Art. 179. A la mujer que para ocultar su deshonra, provocare su propio aborto o lo consintiere. Art. 180. Al que, en el caso del artículo anterior y con el consentimiento de la mujer, provocare el aborto. Calificación por el resultado. Art. 181. Cuando, en el supuesto del artículo precedente, a consecuencia de las maniobras abortivas, sobrevinierre la muerte de la mujer. Tentativa. Art. 182. Cuando, en el caso Definición del artículo 180. el hecho no fuere consumado, la sanción podrá ser libremente atenuada para los partícipes. Inhabilitación especial. Artículo 183. Si el culpable de alguno de los delitos previstos eb los artículos 174 a 182, inclusive, fuere persona que ejerciere una profesion sanitaria. Aborto Autorizado. Art. 184. No constituye delito el aborto practicado por un médico, con el consentimiento de la mujer, cuando se hiciere para evitar un peligro para la vida o la salud de la grávida, esi este peligro no pudiere ser evitado por otros medios. El consentimiento no será necesario cuando la paciente, por incapacidad o por su estado, no se encontrare en condiciones de otorgarlo. Aborto preterintencional. Art. 185. Al que causare un aborto, sin intención de provocarlo, por haber empleado violencias contra la mujer. Aborto culposo. Art. 186. Al que lo causare por culpa, si el embarazo fuere evidente o le constare

Art. 174. 3 a 10 años. Art. 175. prisión de 1 a 5 años. Pero si la mujer fuere menor de 14 años o no tuviese la capacidad de comprende o querer o si el consetimiento se lograre con violencia, amenaza o engaño: prisión de 3 a 10 años.176. $1^{\circ}$ en el caso del art. 174 o de los incisos $1^{\circ}$ y $2^{\circ}$ del art. 175 , prisión de 3 a 15 Pena -para años. $2^{\circ}$ en el primer párrafo del Art. 175, prisión de 2 a 8 años. la mujerArt. 178. prisión de 1 a 5 años. La tentativa no será punible. Art. 179.prisión de 1 a 3 años. 180.1 a 3 años. Art. 181. en caso de muerte, prisión de 2 a 8 años. Lesiones 1 a 5 años. Art. 183. inhabilitación especial por doble tiempo que de la condena y perpetua en caso de reincidencia. Art. 185. Prisión de 6 meses a 2 años. Art. 186. multa de 500 a 20 mil pesos.
Art. 139. Al que causare aborto (sin consentimiento). Con consentimiento de la mujer. Art. 140. Si resultare la muerte de la mujer como consecuencia de las maniobras abortivas y lesiones. 141. A la mujer que causare su propio aborto, o consintiere en que otro se lo practicare.142. El consentimiento de la mujer no será válido: $1^{\circ}$ si contare diez y seis (sic) años o menos; $2^{\circ}$ si padeciere enfermedad mental, insuficiencia de sus aptitudes psíquicas, o trastorno mental transitorio. $3^{\circ}$ si se obtuviere mediante engaño, violencia o intimidación.143.Al que causare u aborto por culpa. 144. Si en los casos de los art. 139 y 141 intervienen como autores o par'ticipes personas que ejercen la medicina o sus ramas conexas o auxiliares. Art.145. La mujer embarazada en la situación prevista en el artículo 192 (violación), que causare su propio aborto o consintiera que otro se lo practicare, y los que hubieren participado en este último hecho, podrán ser exentos de pena. Si la mujer fuere incapaz se requerirá el consentimiento de su representante legal

Art. 139. prisión 2 a 10 años. Con consentimiento, prisión 1 a 6 años. Art. 140 prisión 5 a 15 años (sin consentimiento); prisión 4 a 12 años (con consentimiento). Lesiones. prisión 3 a 12 años (sin consentimiento); prisión, 2 a 8 años (sin consentimiento). Art. 141. prisión 1 a 6 años. Deshonra, prisión 6 a 3 años. Art. 143. prisión 6 meses a1 año. Art. 144. demás de las penas previstas, inhabilitación especial por el doble de tiempo. Art. 145. exentos de pena. 
Definición

Definición

\begin{tabular}{ll}
\hline Pena & prisión 1 a 5 años \\
\hline & Art. 117. aborto con o sin consentimiento. El que \\
& causare la muerte de un feto en el seno materno o \\
& mediante su expulsión prematura. 118. aborto pro- \\
& curado. tentativa no es punible. Art. 119 aborto por \\
& causa de honor. Si el aborto hubiera sido cometido \\
& para ocultar la deshonra de la mujer, sea por ella mis- \\
& ma, sea por terceros con el consentimiento de aquel. \\
& Art. 120. aborto impune. No es punible el aborto \\
& practicado por un medico, con consentimiento de la \\
& mujer en cinta: $1^{\circ}$ si se ha hecho con el fin de evitar \\
& un peligro para la vida o la salud de la madre y este \\
peligro no podía ser evitado por otros medios; $2^{\circ}$ si \\
el embarazo proviene de una violación por la cual \\
la acción penal haya sido iniciada. Si la víctima de \\
la violación fuere una menor o una mujer idiota o \\
demente srá necesario el consentimiento de su re- \\
presentante legal. Art. 121. aborto preterintencional
\end{tabular}

A la madre que, para ocultar su deshonra, matare a

A la madre que, para ocultar su deshonra, matare a su hijo durante su nacimiento o mientras se encontrare bajo la influencia del estado puerperal

prisión 1 a 6 años
Art. 117. mujer que consintiere prisión 1 a 4 años. otros, sin consentimiento de la mujer o menor de 16 años:reclusión o prisión de 3 a 10 años. Con consentimeinto: prisión de 1 a 4 años y reclusión de hasta 4 años. muerte, eleva la pena un tercio. Art. 118. mujer 1 a 4 años de prisión,; quienes cooperen prisión hasta 3 años. 119. prisón de hasta 2 años. Muerte, 1 a 4 años de prisión. Art. 121. 6 meses a 2 años.
Las mismas que dispuso Soler en su proyecto.

Fuente: Elaboración propia en base a la información disponible en Zaffaroni, E. R. y Arnedo, M. A (1996). Digesto de codificación penal argentina. Buenos Aires: A/Z editora. 


\section{Referencias bibliográficas}

Baratta, A. (1986). Criminología critica y crítica del derecho penal: Introducción a la sociología juridico-penal. Siglo XXI: Buenos Aires.

Barrancos, D. (2008). Contrapuntos entre sexualidad y reproducción. En S. Torrado (Comp.), Población y bienestar en la Argentina del primero al segundo Centenario (pp. 475-499). Buenos Aires: Edhasa.

Barreneche, O. (2001). Dentro de la ley, todo: la justicia criminal de Buenos Aires en la etapa formativa del sistema penal moderno de la Argentina. Ediciones al Margen: Buenos Aires.

Beruti, J. y Iraeta, D. (1922). La maternidad ilegítima. Comunicación al II congreso nacional de medicina. La Semana Médica, Buenos Aires, No 4.

Beruti, J. (1943). Producción cientifica y cultural, Buenos Aires: s.e.

Biernat, C. y Ramacciotti, K. (2013). Crecer y multiplicarse. La politica sanitaria materno-infantil. Argentina 1900-1960. Buenos Aires: Biblos.

Caimari, L. (2007). Entre la celda y el hogar: dilemas estatales del castigo femenino (Buenos Aires, 18901940). Nueva doctrina penal, (2), 427-450.

Caimari, L. (2012). Apenas un delincuente: crimen, castigo y cultura en la Argentina, 1880-1955. Buenos Aires: Siglo XXI.

Calandria, S. (2014). Entre la honra y la vida: Un análisis microhistórico sobre las mujeres infanticidas en la Provincia de Buenos Aires 1904-1913. E-l@ tina. Revista electrónica de estudios latinoamericanos, 12(47), 1-15. Recuperado de: http://www.redalyc.org/articulo.oa?id=496450644001

Calandria, S. (2017). Madres criminales: aportes sobre el infanticidio y la criminalidad femenina bonaerense en clave sociodemográfica. Población E Sociedad, 24(2), 4-35. Recuperado de: http://ppct.caicyt.gov.ar/ index.php/pys/article/view/10484/pdf

Montero Cartelle, E. (2010). La sexualidad medieval en sus manifestaciones lingüísticas: pecado, delito y algo más. Clío E̋ Crímen: Revista del Centro de Historia del Crimen de Durango, 7, 41-58. Recuperado de: http://www.durango-udala.net/portalDurango/RecursosWeb/DOCUMENTOS/1/1_3438_3.pdf

Cepeda, A. (2011). En los tiempos del test del sapo: justicia, aborto y políticas de población en la Argentina de mediados del siglo. Revista de Estudos Universitários-REU, 37(1), 243-265. Recuperado de: http:// periodicos.uniso.br/ojs/index.php/reu/article/view/601/687

Cesano, J. y Dovio, M. (2009). La criminalidad femenina en el discurso del positivismo criminológico argentino. Córdoba: Editorial Brujas.

Corva, M. A. (2014). Constituir el gobierno, afianzar la justicia: el Poder Judicial de la provincia de Buenos Aires, 1853-1881. Rosario: Prohistoria. 
Cosse, I. (2004). Entre el estigma y la integración: imágenes, estereotipos y representaciones de la filiación ilegítima en la Argentina (1940-1955). En H. Otero (Dir.), El mosaico argentino (pp. 507-549). Buenos Aires: Siglo XXI.

Cosse, I. (2008a). El modelo conyugal en la ciudad de Buenos Aires de la segunda posguerra: el compañerismo de complementariedad y el impulso familiarista. Trabajos y Comunicaciones, (34), 63-94. Recuperado de: https://www.trabajosycomunicaciones.fahce.unlp.edu.ar/article/view/TYC2008n34a04/pdf_75

Cosse, I. (2008b). Ilegitimidades de origen y vulnerabilidad en la Argentina de mediados del siglo XX. Nuevo Mundo Mundos Nuevos. https://doi.org/10.4000/nuevomundo.12502

Di Corleto, J. (2010). Los crímenes de las mujeres en el positivismo: El caso de Carmen Guillot (Buenos Aires, 1914). Revista Pensamiento Penal, 19-30. Recuperado de: http://www.pensamientopenal.com.ar/ system/files/2015/01/doctrina40524.pdf

Di Liscia, M. (2000). Mujeres, maternidad y peronismo. La Pampa: Fondo Editorial.

Escriche, J. (1852). Diccionario razonado de legislación y jurisprudencia. México: Librería de Rosa, Bouret y cia.

Fairclough, N. (1992). Discourse and Social Change. Londres-Nueva York: Routledge.

Felitti, K. (2012). La revolución de la píldora: sexualidad y política en los sesenta. Buenos Aires: Edhasa.

Foucault, M. (2007). Los anormales. Buenos Aires: FCE.

Giordano, V. (2014). (Doble) moral sexual y derechos civiles de las mujeres, 1888-2010. En D. Barrancos, D. Guy y A. Valobra (Eds.), Moralidades y comportamientos sexuales. Argentina, 1880-2011 (pp. 389-407). Buenos Aires: Biblos.

Giordano, V. (2012). Ciudadanas incapaces: la construcción de los derechos civiles de las mujeres en Argentina, Brasil, Chile y Uruguay en el siglo XX. Buenos Aires: Teseo.

Giordano, V. (2013). La sanción de la capacidad civil plena de la mujer en los países del Cono Sur, 19451990. Una propuesta de análisis del fenómeno legal. Latin American Research Review, 48(3), 25-43. Recuperado de: https://lasa.international.pitt.edu/LARR/prot/fulltext/vol48no3/48-3_25-43_Giordano. pdf

Gonzalez Roura, O. (1922). Derecho Penal, Buenos Aires: Abeledo.

Htun, M. (2003). Sex and the State: Abortion, Divorce, and the Family Under Latin American Dictatorships and Democracies. Cambridge: University Press.

Ini, M. G. (2000). Infanticidios: Construcción de la verdad y control de género en el discurso judicial. En F. Gil Lozano, V. Pita y M. G. Ini (Comps.), Historia de las mujeres en la Argentina (pp. 235-251). Buenos Aires: Taurus.

Juliano, D. (2009). Delito y pecado. La transgresión en femenino. Política y Sociedad, 46(1/2), 79-95. Recu- 
perado: http://revistas.ucm.es/index.php/POSO/article/view/POSO0909130079A

Klein, L. (2005). Fornicar y matar: el problema del aborto. Buenos Aires: Planeta. Larrandart, L. (2000). Control social, derecho penal y género. En H. Birgin, El género del derecho penal: las trampas del poder punitivo. Buenos Aires: Biblos.

Ledesma Prietto, N. (2015). Entre la mujer y la madre. Discursos médicos y la construcción de normas de género (Argentina, 1930-1940). Trabajos y Comunicaciones, (42), pp.1-15. Recuperado en: http://www. memoria.fahce.unlp.edu.ar/art_revistas/pr.6908/pr.6908.pdf

Ledesma Prietto, N. (2016). La revolución sexual de nuestro tiempo: el discurso médico anarquista sobre el control de la natalidad, la maternidad y el placer sexual. Argentina, 1931-1951.Bueos Aires: Biblos.

Levaggi, A. (2012). El derecho penal argentino en la historia, Buenos Aires. Buenos Aires: Eudeba.

López Camelo, R. y Jarque, G. (2004). Curso de derecho penal. Bahía Blanca: EdiUNS .

Nari, M. (2004). Politicas de maternidad y maternalismo politico. Buenos Aires, 1890-194. Buenos Aires: Biblos.

Peco, J. (1943). Proyecto de Código Penal. Exposición de motivos. Presentado el 25 de septiembre de 1941, 1941. Congreso Nacional: Buenos Aires.

Perón, J. D. y Gache Pirán, B. (1951). Código Penal Proyecto del Poder Ejecutivo. Buenos Aires: Dirección de publicaciones, biblioteca y archivo.

Pinto Bouquet, H. (1942). Código Penal Concordado. Buenos Aires: Editorial Mor.

Prósperi, A. (2016). Infanticide, Secular Justice, and Religious Debate in Early Modern Europe. Brepols: Turnhout.

Ramacciotti, K.y Valobra, A. (2004). Generando el peronismo. Buenos Aires: Estudios de Cultura.

Ramacciotti, K. (2006). Las voces que cuestionaron la política sanitaria del peronismo (1946-1949). En J. Suriano y D. Lvovich (Comps.), Las politicas sociales en perspectiva histórica (pp. 169-195). Buenos Aires: Prometeo-Universidad Nacional de General Sarmiento.

Ruggiero, K. (1994). Honor y maternidad y el disciplinamiento de las mujeres frente al infanticidio en el Buenos Aires de finales del Siglo XIX. En L. Fletcher (Edit.), Mujeres y cultura en la Argentina del siglo $X I X$ (pp. 227-235). Buenos Aires: Feminaria.

Sau, V. (1981). Diccionario ideológico feminista. Barcelona: Icaria Editorial.

Scott, J. (1985). Género e historia, México: Fondo de Cultura Económica.

Sedeillan, G. (2012). La justicia penal en la provincia de Buenos Aires: instituciones, prácticas y codificación del derecho (1877-1906). Buenos Aires: Biblos. 
Soler, S. (1960). Proyecto de Código Penal. Buenos Aires: Ministerio de Educación y Justicia de la Nación.

Sozzo, M. (2011). "Los exóticos del crimen”: inmigración, delito y criminología positivista en la Argentina (1887-1914). Delito y sociedad: revista de Ciencias Sociales, 2(32), 19-52. https://doi.org/10.14409/dys. v2i32.5647

Sozzo, M. (2015). Locura y crimen. Nacimiento de la intersección entre los dispositivos penal y psiquiátrico. Buenos Aires: Ediciones Didot.

Speckman Guerra, E. (2002). Crimen y castigo. Legislación penal, interpretaciones de la criminalidad y administración de justicia (Ciudad de México, 1872-1910). México: Universidad Nacional Autónoma de México.

Suriano, J. (2004). La cuestión social en Argentina: 1870-1943. Buenos Aires: La Colmena.

Tejedor, C. (1871). Curso de derecho criminal. Buenos Aires: Librería de Cl. M. Joly.

Tejedor, C (1867). Proyecto de Código Penal. parte II, edición del año 1867. En G. Cabanellas (1945). El aborto. Su problema social, médico y jurídico (pp. 263-264). Buenos Aires: Atalaya.

Valobra, A. (2005a). De cronopios y de famas.» La atención del binomio madre-hijo en la política sanitaria bonaerense durante la gobernación de Domingo Alfredo Mercante, 1946 y 1952. En C. Panella (Comp.), El gobierno de Domingo Mercante. Un caso de peronismo provincial (pp. 129-172). La Plata: Instituto Cultural y Archivo Histórico de la Provincia de Buenos Aires.

Valobra, A. (2005b). Public health policies, women's organizations and mothers in the province of Buenos Aires, 1946-1952. Studies in Social Sciences, 38, 79-95.

Vassallo, J. (2006a). Delincuentes y pecadoras en la Córdoba tardo colonial. Anuario de Estudios Americanos, 63(2), 97-116. https://doi.org/10.3989/aeamer.2006.v63.i2.21

Vassallo, J. (2006b). Mujeres delincuentes: una mirada de género en la Córdoba del siglo XVIII. Córdoba: Centro de Estudios Avanzados,-Universidad Nacional de Córdoba.

Yangilevich, M. (2012). Estado y criminalidad en la frontera sur de Buenos Aires, 1850-1880. Rosario: Prohistoria.

Zaffaroni, E. R. y Arnedo, M. A. (1996). Digesto de codificación penal argentina. Buenos Aires: A/Z editora.

Zimmermann, E. (1995). Los liberales reformistas: la cuestión social en la Argentina, 1890-1916. Buenos Aires: Editorial Sudamericana. 